\title{
Action Research on Teaching of Creative Writing for Postgraduates
}

L. Li

Northwestern Poly-technical University, Shaan Xi, China

\begin{abstract}
English writing is a tough course for post-graduate students in science universities. Traditionally the students are instructed and trained in order to pass a national examination, CET-6. Most students just recite writing models of argumentative, enjoying no right to do creative writing. But an investigation has shown that students are eager to write something creative, critical and interesting. Based on the investigation, I began the classroom teaching of argumentative writing followed by appreciation of English speech. During the teaching, problems arose and an action study was carried on to find out the reasons and solutions. Finally the conclusion has been reached that writing task with interaction and appropriate difficult can help motivate students. Students are more likely to write more creative in a relaxing and intensive class.
\end{abstract}

KEYWORD: Action study; English writing

\section{INTRODUCTION}

\subsection{Importance of English Wring Creatively}

English writing is a demanding course than reading in science universities. Traditionally postgraduate students are instructed and trained in order to pass a national examination, CET-6. Most students just recite writing models of argumentative, enjoying no right to do creative writing.

Teaching writing only with purpose of passing examination kills student's interest in writing and destroys their creativity. Stereotyped writing models limit student's originality, though they may be improved in their scores. The destructive results are profound and influential. No writing interest and no applied writing skills are just among them.

An investigation to 300 students and an interview with 30 students have shown that postgraduate students majored in science are eager to be trained and to write something creative and critical. Students believe their writing ability (not only in English) needs urgent promotion and their confidence can be improved. As a teacher, I find English speech is a valuable part for teaching English writing as English is the only course of humanities that students lay emphasis on in college. Therefore, not only English language writing but also the whole culture and history knowledge is to be instructed in the classroom teaching of English language writing. It is also an effective way not only to help them with their mastery of the language but also to familiarize them with some culture and history knowledge.

\subsection{Classroom Teaching of Writing Creatively}

Based on the investigation, I carried on the classroom teaching and practice of creative English writing followed by appreciation of English public speech. However, during the first semester of teaching creative English writing based on speech draft, problems arose. Famous speeches from some celebrities of UK and USA were selected to give students "in-put". Difficult language points in each speech were explained first, which would cost one hour for each speech. After that students would be asked to prepare a speech draft on a topic similar with that they read and turned in. In the following week, they would be divided into groups to have a speech contest with their speech drafts within each group.

The classroom teaching was expected to be efficient and instructive. But after a semester two major problems arose with the new teaching method. The first is that students showed no interest in appreciating the famous English public speech. That is to say, they cannot digest the "input". Secondly, students were not interested in competing within their group. During the contest, the students who were not speakers did not attend to the speakers and 
they played mobile phones, chatted, read their own speeches and so on. When students could not appreciate the input, they showed no inters in writing on a similar topic. Under the circumstance, the class of writing creatively is even worse than that of writing with stereotyped patterns for examination.

An action research was conducted in order to solve the dilemma in this new writing teaching method (Richards \& Lockhart, 2000).

\section{ACTION RESEARCH OF CLASSROOM TEACHING}

\subsection{Planning}

\subsubsection{Problems}

The first problem is that students showed no interest in appreciating the famous English public speech. That is to say, they cannot digest the "input".

Secondly, when students were asked to compete within each group, they felt unmotivated and bored. Therefore, they did something more than attending to the speeches. The speaker might be embarrassed because nobody was his real audience. Later on, he or she lost interest in both writing and speaking.

\subsubsection{Possible reasons}

In order to solve the two problems, such ways as observation, questionnaire and interview have been carried on to search for possible reasons.

First of all, an observer was invited to come into the writing class so as to observe the performance of students as a passive participant. She is a young colleague and knew exactly what to observe in my class, i.e. to observe the students' reaction toward the handout of the public speech that teacher would deliver. She was asked not to interfere with any students' discussion or talking no matter what they were doing or saying. During the two hours of attending to the class, she observed and noted down some of the students murmuring. She participated in their talking and discussions, but mainly followed what the students said and did. Generally speaking, she just role-played as one common student. After the class, she analyzed her notes and concluded that the speech itself was too hard and beyond the students' appreciation. They were exhausted after reading once. Such a conclusion was based on the students murmuring as "So many new words!", "Oh, it comes again!', "So boring!" and so on. During her talk with students, she found they were not interested in reading those tough tasks in a writing class. They were too tired in reading to do any writing and speaking. When they were not confident with their speech drafts, they felt awkward to make public speeches with the drafts.
Then a questionnaire investigation was conducted based on her observation and similar conclusion was obtained.

There might be three reasons causing students' disinterest in appreciating the public English speech. Firstly, the speech itself is too difficult for students to understand, let alone to appreciate. Some famous speeches by American presidents or statesmen are quite difficult in language itself, both in vocabulary and rhetoric, which are beyond the level of nonEnglish majors. Secondly the teaching pattern of explaining the difficult language points is too outdated for students. They might feel it is like a reading class. Therefore they showed no interest in it.

To solve the second problem, interviewing with both colleagues and students was conducted to find out the potential reasons. Thereafter, the reasons are listed as follows. 1) There was no teacher's grading, correction and assessment. 2) They could not see any point in attending to others' speeches. 3) students didn't know how to make public speech and simply was reading their drafts.

\subsubsection{Possible solutions}

Conclusion was reached about how to solve the two problems based on discussion, consultation and searching for useful information in related literature.

With regard to the first problem, the following methods would be carried on. Firstly, those speeches with video material were preferred in the class, which would be more vivid and easier for students to follow in classroom teaching. These speeches may not be delivered from such celebrities as presidents, prime minister or laureates. The readability for the level of non-English-majored postgraduates is of priority. Most important of all, the speech itself is not supposed to be too hard. Then difficult language points would be explained in class as usual. The background of the speeches, cohesion and organization of the speeches would be focus in class. To help comprehension, Chinese versions of the speeches would be offered for them to read by themselves after class. At last half an hour would be left for students to appreciate the speech vividly with video. The gestures, dressing, intonation and facial expressions could all be explained and stressed for students to follow.

As for the second problem, the organization and management of class would be enhanced to promote students' involvement and interaction. Altogether 8 writing tasks would be assigned for students to finish in one academic semester. The first speech was the easiest one among all the speeches collected for the students to appreciate. For each task, students would first write a draft for peers to grade, and then they turned in after the first revision. After teacher finished grading, students would be divided into 4-5 groups. And it's left for them to select one speaker 
with the best draft to compete in the whole class. When the contestants were making their prepared speech, all the rest students had to grade them with a grade sheet.

\subsection{Action}

Then in the following semester, an action based on the above planning was conducted to improve the classroom teaching of creative English writing. The following is a timetable of classroom management (see table 1).

Table 1. Arrangement of one writing task

\begin{tabular}{|l|l|l|}
\hline Length & Teacher's s activity & Students' activity \\
\hline 20minutes & $\begin{array}{l}\text { explain difficult language } \\
\text { points in speech draft and } \\
\text { read new words for } \\
\text { students to follow }\end{array}$ & $\begin{array}{l}\text { Read after teacher } \\
\text { and brainstorm } \\
\text { about their speech } \\
\text { drafts }\end{array}$ \\
\hline $\begin{array}{l}\text { Play video material; } \\
\text { underline gestures, tones } \\
\text { and postures of the } \\
\text { speaker }\end{array}$ & $\begin{array}{l}\text { Attend to the } \\
\text { video material }\end{array}$ \\
\hline After class & Grade & Prepare drafts \\
\hline 10 minutes & host the speech contest & Select contestants \\
\hline 40 minutes & attend to speech contest & $\begin{array}{l}\text { Contestants make } \\
\text { their speeches }\end{array}$ \\
\hline
\end{tabular}

\subsection{Observation}

Three observers were asked to attend to a full unit of the writing class. The first was the one who had attended to my class as mentioned above. She paid special attention to the teaching unit in which a speech was comprehended and appreciated by students under the new teaching approach. An experienced professor was also invited to my class to give special comment to the teaching unit in which students presented their speeches. Another student from the class mentioned in Planning was finally asked to re-attend to the class in the new semester. At the same time, the whole speaking turn of four students' speeches were recorded. The following is all the observation results.

1. The student showed obvious interest in the video material of the speech by saying that he would want to attend to the class. He also agreed that this new approach would help students understand the speech draft better and save more time with the Chinese version of draft after class. The video material presented in class can help students to learn to how to speak in public, not only in English. And the part he showed most appreciation in the new teaching approach is that teacher reads some new and difficult words and sentences aloud in class for students to follow. For students don't really pay attention to phonetic symbol in English and they pronounce new words in Chinese way.

2. The colleague who had come to my class twice also noted down some of the students' response to the speech presented in English with Chinese translation. She found students did have a better and deeper comprehension of the speech and showed definitely more interest in appreciating the video material by following the speaker. She also found that some students were even imitating the speaker's stress, intonation and pronunciation in the video when I was underlining some difficult or topic or shining sentences in the speech. But on the other hand, students would only refer to the translation whenever they ran into some new words and difficult sentences. Students may depend too much on the translation.

3. The professor who was asked to appreciate the students' speeches commented as follows: students performed better than she had expected; students were more attentive to this combination of writing and oral task than to a single writing activity and the single oral activity such as group discussion, answering question, picture description and so on; teacher really plays a role of monitor and organizer, which is good; only limited number of students were speaking in a class of 50 minutes, which needs improving.

\subsection{Reflection}

The English writing class in the second year becomes better than that in the first year after some adjustment. The conclusion comes from students' reflection, observer's observation and comments. The adjustment leading to this result is as follows.

1. Multimedia input materials are presented for students in class to supplement the printed speech text for them to appreciate, to follow and to imitate.

2. Every student is supposed to participate in the class not only as writer but also as speaker.

3. The teacher mainly acts as an organizer and a monitor (which is like a hostess in an Evening.) instead of the traditional lecturer.

\section{CONCLUSION}

From the adjustment and conclusion, we can see that Teaching creative writing is fresh and demanding in science universities in China for most teachers and students only stressed their scores of examination. However, students, esp. students of advanced level and those between intermediate and advanced level are tired of the traditional class of teaching writing. They would like to write creatively and critically. Next, students would like to involve in class by 
speaking. But in China, it is quite hard for teachers to involve everyone into speaking in a single teaching period. Under these circumstances teachers have to come up with original ideas and approaches to encourage students to attend to class not only by speaking but also by writing. Furthermore, motivation, encouragement and interaction are more decisive to a successful classroom teaching than teacher's excellent spoken English. A teacher liked by students tends to motivate and encourage students to learn by themselves. In an interesting, relaxing and intensive class, students are more likely to learn more. Finally, teaching is an open system which does not end at a termination and which always wants progress and adjustment. A teacher can always find problems with his or her classroom teaching because the subjects to whom we are teaching are subjected to change. Therefore, every teacher needs to do research on his or her class ever semester (Wallace, 2003). As is mentioned, there are still problems after the adjustment.

\section{REFERENCES}

[1] Richards, J.C. \& Lockhart, C. 2000. Reflective Teaching in Second Language Classrooms. Cambridge: Cambridge Press.

[2] Wallace, M. 2003. Action Research for Language Teachers. Beijing: People's Education Press. 